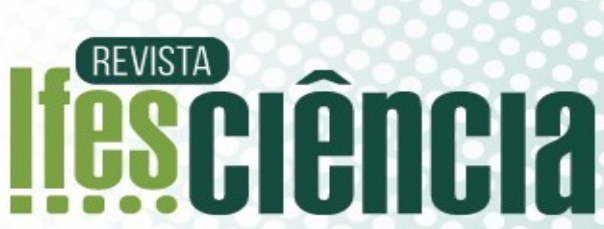

\section{A HUMANIZAÇÃO EM AMBIENTES HOSPITALARES: ESTUDOS DE CASO NA CIDADE DE COLATINA-ES}

\section{HUMANIZATION IN HOSPITAL ENVIRONMENTS: CASE STUDIES IN THE CITY OF COLATINA, ES}

\begin{abstract}
Micaela Scarpatti Jogaib Dutra ${ }^{1 *}$ Giusilene Costa de Souza Pinho ${ }^{2}$ Renilson Luiz Teixeira ${ }^{3}$

${ }^{1}$ Graduanda do curso de Arquitetura e Urbanismo no Instituto Federal do Espírito Santo, Ifes Campus Colatina, Colatina-ES. Email: micascarpati@live.com. ${ }^{2}$ Mestra em Engenharia Civil (2012). Doutoranda em Engenharia Ambiental. Professora de Arquitetura e Urbanismo no Instituto Federal do Espírito Santo, Ifes Campus Colatina, Colatina-ES. Email: giusilene.pinho@ifes.edu.br.

${ }^{3}$ Doutor em Ciência e Tecnologia da Madeira (2013). Professor de Arquitetura e Urbanismo no Instituto Federal do Espírito Santo, Ifes Campus Colatina, Colatina-ES, Email:renilson@ifes.edu.br.

*Autor para correspondência
\end{abstract}

Artigo submetido em 29/10/2019, aceito em 06/12/2019 e publicado em 23/12/2019.

Resumo: Com o passar do tempo as unidades de saúde começaram a se preocupar com a assepsia do local e colocar o paciente como foco, visto que anteriormente eram vinculados a locais de dor e sofrimento, trazendo assim, o conceito de humanização para dentro dos espaços hospitalares. Dentro deste contexto, o presente trabalho tem por objetivo fazer um diagnóstico dos principais hospitais da cidade de Colatina-ES em relação a humanização de seus espaços. O método de análise foi a matriz FOFA (Fortalezas, Oportunidades, Fraquezas e Ameaças) para detectar os pontos fortes e frágeis dos ambientes, tendo como referencial a Cartilha Humaniza SUS (Sistema Único de Saúde), do Ministério da Saúde, (BRASIL, 2010). Os resultados mostram que embora este material tenha sido publicado pelo governo, muitos pontos não estão sendo atendidos pelas redes públicas pesquisadas, mostrando que as instituições de saúde governamentais carecem da maioria dos itens previstos para proporcionar o bem-estar do paciente e assim auxiliar no processo de saúde.

Palavras-chave: Humanização; Espaço Físico; Políticas de saúde; Ambiência; Confortabilidade.

Abstract: Over time the health units began to worry about the asepsis of the site and focus the patient, since they were previously linked to places of pain and suffering, thus bringing the concept of humanization into hospital spaces. Within this context, the present work aims to make a diagnosis of the main hospitals of the city of Colatina-ES in relation to the humanization of their spaces. The method of analysis was the S.W.O.T (Strengths, Weaknesses, Opportunities, Threats) analysis to detect the strengths and weaknesses of the environments, having as reference the Humaniza SUS booklet of the Ministry of Health (BRAZIL, 2010). The results show that despite of this material has been published by the government, many points are not being reported by the public networks surveyed, pointing that government health institutions lack most of the items specifyed to provide patient well-being and thus assist in the health process.

Keywords: Humanization; Physical space; Health policies; Ambience; Comfortability. 


\section{INTRODUÇÃO}

No período medieval, os hospitais foram vinculados à representação de morte, de angústia e de sofrimento. Isso se dá, sobretudo, porque nessa época eles serviam para isolar pessoas doentes e pobres do convívio social e, desse modo, evitar a contaminação de outros indivíduos. Ainda, no Hospital não existiam perspectivas de cura, visto que a função da medicina não era exercida neste local. Tratava-se apenas de um lugar insalubre, com pouca ventilação e iluminação, pois acreditavam que $\mathrm{o}$ ar poderia transmitir doenças infecciosas e epidêmicas, que confinava os enfermos (LUKIANTCHUKI e SOUZA, 2010).

A partir do final do século XVIII, no período Iluminista e da Revolução Industrial, iniciou-se uma preocupação maior em relação ao homem, tanto no meio assistencial quanto no físico. Segundo Foucalt (1989), foi em torno de 1780 que se teve a consciência de que o hospital deveria ter como função a cura do paciente. Com a evolução da ciência e desmistificação sobre o papel da ventilação e iluminação, foi criado um novo modelo hospitalar, o pavilhonar, que tinha como princípio central a ventilação natural e a insolação. As funções eram dispostas por pavilhões separados que buscavam conforto e higiene, proporcionando também contato com o exterior, tentando fazer com que o ambiente se tornasse mais familiar. Percebe-se que foi nesse período que o conceito de humanização começou a ser implantado (RAMOS e LUKIANTCHUKI, 2015).

Para Deslandes (2006), a

humanização, no âmbito geral, baseia-se na relação de igualdade, nas quais as ideias de inferioridade e superioridade são contrastantes com o conceito, ressaltando o sentido de reciprocidade e empatia entre os indivíduos. Essa definição se aplica tanto ao quesito de tratamento entre os usuários quanto a criação do ambiente.

Dentro do contexto da humanização, o termo é relacionado de três formas como contribuição ao serviço de saúde, sendo elas: a assistencial, na qual se refere à alteração na prática dos profissionais em relação ao contato com os pacientes, tornando-as mais cordiais e pessoais; o ambiente físico que geralmente se remete a presença de cores, iluminação, vegetação, entre outros; e a institucional que visa tornar a imagem atrativa à clientela pretendida (LOPES; MEDEIROS, 2004).

A partir da preocupação instaurada no século XVIII, os hospitais se tornaram cada vez mais modernos e preocupados com a assepsia do local. Entretanto, ainda existia a problemática sobre a forma como a arquitetura hospitalar se apresentava. Em vários locais, ainda é intimidadora, desencadeando sensações desagradáveis para muitos usuários. Paredes brancas, vidros, corredores grandes e impessoalidade são típicas características da tipologia atual da maioria dos hospitais no mundo, não proporcionando, muitas vezes, o bem-estar ao paciente. Sendo assim, vê-se a necessidade da criação de um espaço hospitalar mais humanizado.

Com a arquitetura é possível criar espaços que influenciam os sentidos, como emoções e humor dos usuários, afetando tanto a saúde psíquica, quanto também a emocional (LA FUENTE, 2013). Pallasmaa (2011) acredita que a vivência da arquitetura é multissensorial, dado que todos os atributos do local são percebidos no mesmo momento, no qual se fundem entre si e reafirma nossa identidade pessoal. Para Gibson (1966, apud Neves, 2017), os impulsos sensoriais podem ser definidos pelas ações dos humanos no ambiente ou até mesmo pelo próprio espaço em questão.

De acordo com Vianna et al. (2008), o ambiente físico influi no processo de tratamento do paciente, dado que ele possui capacidade de reduzir o estresse e ansiedade dos usuários, além de diminuir a dor, reduzindo a necessidade de uso de remédios. Entretanto, é levantado por Lopes e Medeiros (2004) que os profissionais da saúde têm focado na doença como algo 
relacionado apenas ao corpo, não levando em consideração o contexto social em que os pacientes estão inseridos e os aspectos psicológicos.

$\mathrm{Na}$ busca da redução da impessoalidade causado pelo avanço tecnológico na área da saúde, a humanização tem sido ferramenta de auxílio para a mudança desse cenário. No campo arquitetônico, "ambiente humanizado" é uma expressão utilizada para remeter a locais "aconchegantes" e provedores de bem-estar ao usuário, trazendo mais familiaridade e identificação com o local (LOPES; MEDEIROS, 2004).

A humanização, de acordo com Ramos e Lukiantchuki (2015), pode ser praticada de várias maneiras na arquitetura, entretanto, três são destacadas: a humanização do ambiente através da utilização de artes visuais; o uso dos condicionantes naturais, como ventilação e iluminação natural; e o uso de vegetações visando o bem-estar ambiental.

Assim, o presente trabalho tem por objetivo fazer uma análise dos principais hospitais da cidade de Colatina-ES através da matriz FOFA (Fortalezas, Oportunidades, Fraquezas e Ameaças) auxiliando na organização e observação dos pontos negativos e positivos do espaço, em relação a humanização de seus ambientes. Os referenciais de análise foram os itens discorridos pela Política Nacional de Humanização (PNH) elaborada no Brasil. Através desta pesquisa, foi constatado que, a maioria dos hospitais analisados, necessitam de intervenções para tornar seus espaços provedores saúde.

\section{REFERENCIAL TEÓRICO}

\subsection{AMBIENNCIA}

Todos os ambientes em que vivemos e frequentamos afetam nossas sensações, podendo elas serem positivas ou negativas. A Psicologia Ambiental é uma vertente da psicologia que estuda diretamente a relação bidirecional pessoa-ambiente (CAVALCANTE e ELALI, 2011).
Corroborando com o assunto, Pinheiro (2006) relaciona esse estudo com a "interação do homem com seu ambiente para desenvolver estratégias e ferramentas de aplicação e intervenção que contribuam para a mudança dessa relação de forma mais consciente". Sendo assim, o conhecimento de como o local influencia na relação pessoa-ambiente contribui para um melhor planejamento do projeto de arquitetura, visando o bem-estar do usuário.

Essas sensações são relacionadas com as experiências e as percepções de cada pessoa sobre o ambiente, sendo esse sentido do espaço, de acordo com Hall (1997), uma síntese de vários insumos sensoriais, como o visual, auditivo, cinestésico, olfativo e térmico. Além deles, outros aspectos também influenciam, sendo eles os sociais, culturais e físicos (MARTORELLI, 2015).

No campo da Arquitetura e Urbanismo esse conceito de ambiência tem sido considerado de suma importância na compreensão de como utilizar o espaço e realizar o seu projeto (ELALI, 2009). Dentro do âmbito da saúde, o Ministério da Saúde define esse termo se referindo "ao tratamento dado ao espaço físico entendido como espaço social, profissional e de relações interpessoais que deve proporcionar atenção acolhedora, resolutiva e humana" (BRASIL, 2010).

Atualmente, assim como no movimento moderno com o estilo internacional, que expressava em sua arquitetura a medicina com alta tecnologia, havendo a submissão da estética pela funcionalidade, nos interiores dos hospitais brasileiros predominam a falta de ornamentos e cores e seguem um modelo ergonômico padronizado, além dos tetos planos e estrutura em concreto e aço com grandes vãos de vidro, predominando na fachada (LOPES e MEDEIROS, 2004). Contrapondo a essa falta de humanização, Miquelin (1997) menciona que se devem multiplicar exemplos de hospitais humanizados, semelhantes a hotéis, ao ponto de entrarem em um hotel planejado e compararem a um hospital. 
De acordo com Bromley (2012), dentro do design hospitalar e também no campo da assistência médica, vem ocorrendo maior preocupação com $\mathrm{o}$ conforto do paciente, concentrando na melhoria da sua experiência dentro do ambiente hospitalar. Tem sido cada vez mais comum a utilização de artifícios de design que visam tornar os espaços mais acolhedores e com serviços análogos a hotéis aos usuários (BROMLEY, 2012).

A sensação de conforto é relativa, corresponde de acordo com as necessidades de cada indivíduo e sua integração com o ambiente, não envolvendo apenas critérios acústicos, visuais, térmicos ou até mesmo químicos, mas também levando em consideração a emoção e o prazer, visto que o ambiente construído atua como morada tanto para o corpo quanto para a alma (BESTETTI, 2014).

Para Ulrich (1991), alterar o espaço visando a redução do estresse ambiental auxilia na cura do paciente e reduz os custos com o tratamento. Dentro das características de um espaço humanizado que visa o conforto ambiental, encontra-se o aproveitamento da iluminação e ventilação natural, o uso de vegetação e a utilização de artes visuais (RAMOS e LUKIANTCHURI, 2015). No Brasil, existem hospitais referências que utilizam desses recursos objetivando a criação de ambiências agradáveis, remetendo a espaços diferentes dos da saúde, como hotéis. Dentre eles podemos citar as redes Sarah Kubitschek, Albert Einstein e Sírio-Libanês.

\subsection{POLÍTICA NACIONAL DE HUMANIZAÇÃO (PNH)}

Após o período pós-guerra no Reino Unido a ideia de (re) humanização dos hospitais se intensificou, fazendo parte das tendências internacionais. Essas tendências ligavam-se ao estado de bem-estar social e seu modelo remetendo ao sentimento de igualdade, tratando o humano como coletivo e também individual (BATES 2018). Desde 1958 que, na França, o Ministério da Saúde criou uma circular sobre a humanização nos hospitais que mostrava a importância dos cuidados hospitalares humanizados dentro do sistema universal da saúde (NARDIN, 2009).

De acordo com Bates (2018), dentre as propostas, muitas delas se referiam às práticas de trabalho no setor da saúde, com a política assistencialista, entretanto, várias outras sugerem medidas específicas à estética dos hospitais. $\mathrm{O}$ autor ainda comenta que a humanização do cuidado deve ser atrelada ao ambiente em que esse cuidado ocorre.

No Brasil, visando disseminar o conceito de humanização, o Ministério da Saúde (MS), em 2003, criou uma Política Nacional de Humanização (PNH) na qual produziu cartilhas intituladas como "Humaniza SUS", explicando e exemplificando como tornar o espaço de saúde mais humanizado.

É entendido pela cartilha como humanização, a valorização de todas as pessoas presentes no processo de produção de saúde, tendo como diretrizes da política a autonomia e o protagonismo dos usuários do ambiente em questão, a corresponsabilidade entre esses sujeitos, os vínculos e participação dos mesmos no processo de gestão (BRASIL, 2010).

Corroborando com o assunto, é compreendido pelo Ministério (BRASIL, 2010) que o conceito de ambiência se divide em três partes conforme o Quadro 1: 
Quadro 1: Conceitos de ambiência conforme a cartilha Humaniza SUS

(BRASIL, 2010)

\begin{tabular}{|c|c|}
\hline Confortabilidade & $\begin{array}{l}\text { Proporcionar } \\
\text { privacidade e } \\
\text { individualidade } \\
\text { dos usuários, } \\
\text { considerando os } \\
\text { elementos do } \\
\text { ambiente que se } \\
\text { comunica com } \\
\text { as pessoas como } \\
\text { a cor, cheiro, } \\
\text { som, } \\
\text { iluminação, } \\
\text { morfologia, } \\
\text { entre outros, } \\
\text { além de garantir } \\
\text { o conforto a } \\
\text { aqueles que } \\
\text { utilizam. }\end{array}$ \\
\hline Produção de Subjetividade & $\begin{array}{l}\text { Possibilitar } \\
\text { encontro de } \\
\text { sujeitos, por } \\
\text { meio de ações e } \\
\text { reflexões sobre } \\
\text { o trabalho. }\end{array}$ \\
\hline $\begin{array}{l}\text { Facilitador no processo do } \\
\text { trabalho }\end{array}$ & $\begin{array}{ll}\text { Auxiliar } & \text { na } \\
\text { otimização } & \text { de } \\
\text { recursos, } & \text { no } \\
\text { atendimento } & \\
\text { humanizado, } & \text { de } \\
\text { maneira } & \\
\text { acolhedora } & \text { e } \\
\text { eficaz. } & \end{array}$ \\
\hline
\end{tabular}

Fonte: Elaborada pelos autores (2019)

Tendo em vista a criação de espaços acolhedores que propiciem bem-estar aos usuários e que auxiliem no processo de cura do paciente, são abordados os seguintes pontos: Morfologia, usada através de volumes ou formas na criação de espaços; luz, sendo ela artificial ou natural, contribuindo para uma ambiência mais aconchegante, além de permitir, com auxílio da fonte natural, a noção de temporalidade; cheiro, identificar os odores característicos dos espaços, visando observar se interfere no bem-estar dos indivíduos; som, se atentar ao conforto acústico do local e estudar a possibilidade de música ambiente; sinestesia, permitir a percepção do espaço através de movimento das texturas e das superfícies.

Além desses, são pontuados também: a arte, funcionando como meio de inter-relação e manifestação dos sentidos humanos; cor, utilizada como meio estimulante às sensações, como relaxamento, divertimento, entre outras; tratamentos das áreas externas, criando ambientes de estar que possam prover relaxamento, além de integração e encontros; privacidade e individualidade, através da criação de ambientes que protegem a intimidade do paciente, oferecendo também espaço para seus pertences, visando o sentimento de acolhimento; e confortabilidade, possibilitando aos usuários acessos aos banheiros e bebedouros, além de criar espaços nos quais os usuários possam identificar seu mundo, com referências do seu cotidiano, sua cultura, entre outros.

É exposto ainda que para a promoção de acolhimento é importante que haja espaços de encontro entre aqueles que circundam o local, onde haverá integração entre os usuários, sendo eles pacientes, acompanhantes e profissionais. Esses espaços devem prover conforto ambiental, podendo ser sentido através da inserção de vegetação, do aproveitamento da iluminação e ventilação natural, cores, artes, entre os outros itens já abordados.

Através do uso e divulgação da Cartilha Humaniza SUS, a criação e reprodução de exemplos de hospitais humanizados é esperada, visando criar mais ambientes que promovam o bem-estar buscando auxílio no processo de cura do paciente.

\subsection{HOSPITAIS HUMANIZADOS}

Segundo Lukiantchuki e Souza (2010), um ambiente humanizado pode ser visualizado a partir de diferentes comparações. As mais recorrentes são: o hotel; a relação com a natureza; a integração com obras de artes; o lar e a possibilidade 
da intimidade e a figura do espaço urbano e do convívio social (Quadro 2).

Quadro 2: Formas em que o ambiente humanizado pode ser analisado de acordo com Lukiantchuki e Souza (2010).

\begin{tabular}{|c|c|}
\hline Características & Aplicação \\
\hline Hotel & $\begin{array}{l}\text { Analogia muito frequente } \\
\text { na arquitetura hospitalar } \\
\text { americana, a qual } \\
\text { acreditava que a forma de } \\
\text { tratar o paciente deveria } \\
\text { ser equivalente a um } \\
\text { cliente de hotel, } \\
\text { resultando assim um } \\
\text { bem-estar maior do } \\
\text { usuário, visando reduzir } \\
\text { sua estadia no local. }\end{array}$ \\
\hline Natureza & $\begin{array}{l}\text { Presença de vegetação, } \\
\text { compondo outra } \\
\text { atmosfera para o local. } \\
\text { Pode ser aplicado por } \\
\text { meio de grandes } \\
\text { avarandados, criando } \\
\text { locais de interação com } \\
\text { os indivíduos e com o } \\
\text { exterior. }\end{array}$ \\
\hline $\begin{array}{l}\text { Integração com } \\
\text { obras de arte }\end{array}$ & $\begin{array}{l}\text { Criação de ambientes } \\
\text { mais descontraídos e } \\
\text { estimulantes. Pode ser } \\
\text { aplicada através das } \\
\text { exposições dos } \\
\text { resultados obtidos em } \\
\text { oficinas aos pacientes, } \\
\text { permitindo ainda a } \\
\text { sensação de } \\
\text { familiaridade dele com o } \\
\text { ambiente. }\end{array}$ \\
\hline Lar & $\begin{array}{l}\text { Tentativa de tornar o } \\
\text { ambiente mais parecido } \\
\text { com o lar, podendo ser } \\
\text { realizado através da } \\
\text { diminuição dos leitos nos } \\
\text { quartos, permitindo } \\
\text { privacidade. Também, } \\
\text { outro meio é possibilitar } \\
\text { que o paciente possa } \\
\text { personificar seu local de } \\
\text { internação, trazendo } \\
\text { intimidade com o local. }\end{array}$ \\
\hline Espaço urbano & $\begin{array}{l}\text { Associada com a } \\
\text { arquitetura hospitalar } \\
\text { francesa contemporânea, } \\
\text { como exemplo o Hospital }\end{array}$ \\
\hline
\end{tabular}

\begin{tabular}{|l|l|}
\hline & $\begin{array}{l}\text { Pediátrico Robert-Debré } \\
\text { (Figura 1), na qual a } \\
\text { edificação se abre para a } \\
\text { cidade por meio de uma } \\
\text { galeria pública, ligando o } \\
\text { hospital a vários terraços- } \\
\text { jardins, promovendo } \\
\text { integração entre aqueles } \\
\text { que frequentam o local } \\
\text { com a sociedade. }\end{array}$ \\
\hline
\end{tabular}

Fonte: Elaborada pelos autores (2019)

Figura 1: Hospital Pediátrico Robert-Debré

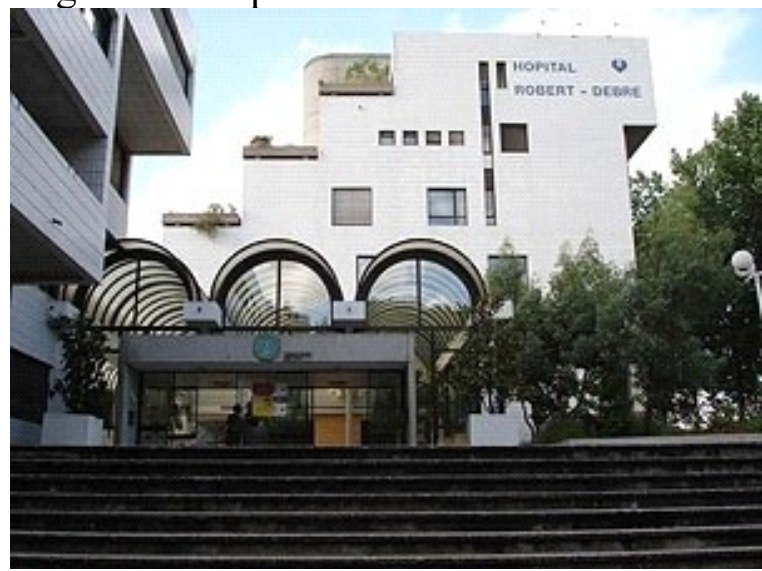

Fonte: Lukiantchuki e Souza (2010)

No Brasil, há hospitais que utilizam da humanização como recurso. Dentre eles, pode-se ressaltar a Rede Sarah, o Albert Einstein e o Sírio-Libanês que se destacam por abordarem os pontos da humanização com todo o cuidado, criando ambientes hospitalares mais confortáveis aos usuários, desvinculando da tipologia das redes de saúde convencionais.

Usando a analogia com o espaço urbano, como o hospital Robert-Debré, o projeto de ampliação do Albert Einstein localizado em São Paulo reconfigurou a entrada e a recepção para o público por meio de uma galeria com um alto pé-direito no térreo, na intenção de substituir os espaços frios por locais mais humanizados, através de uma galeria semi-pública (LUKIANTCHUKI e SOUZA, 2010).

Tanto o Hospital Sírio-Libanês quanto $\mathrm{o}$ Albert Einstein possuem características de hotel, com ambientes aconchegantes, aproveitamento dos condicionantes naturais e integração do interno com o externo, através de grandes 
panos de vidro, trazendo mais conforto aos usuários (Figura 2).

Figura 2: Hospital Sírio-Libanês.

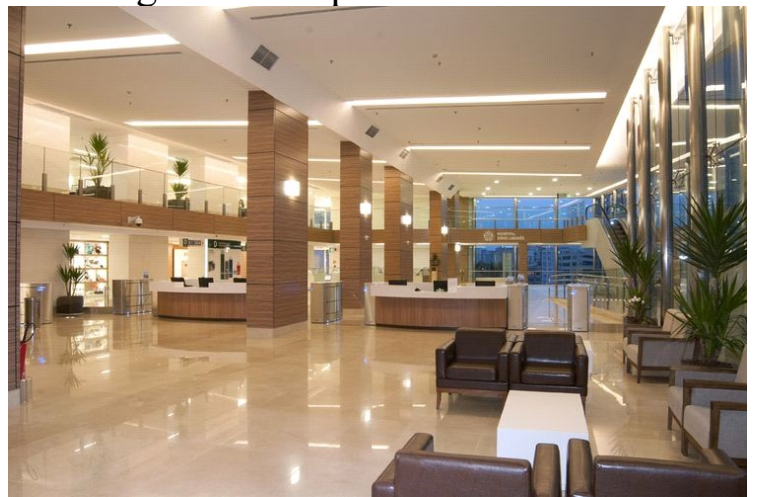

Fonte: HARMONIA ACUSTICA. Hospital Sírio Libanês | bela vista. Disponível em: $<\mathrm{http}$ ://harmoniaacustica.com.br/pt/projetos/hospital -sirio-libanes-bela-vista-2/ >

$\mathrm{O}$ arquiteto dos hospitais Sarah Kubitschek, João Filgueiras Lima, vulgo Lelé, é conhecido por adotar ao longo dos 30 anos, nas 10 unidades da Rede Sarah, estratégias bioclimáticas, visando tornar o ambiente mais confortável (LUKIANTCHUKI e CARAM, 2014). Dentre as medidas adotadas, encontram-se o uso de vegetação, aproveitamento dos condicionantes naturais, inserção de artes, grandes avarandados, entre outros artifícios. Segundo ele, apesar dos projetos de edifícios hospitalares serem mais complexos e rigorosos em relação a funcionalidade, a beleza não deve ser deixada de lado (LIMA, 2004) (Figura 3).

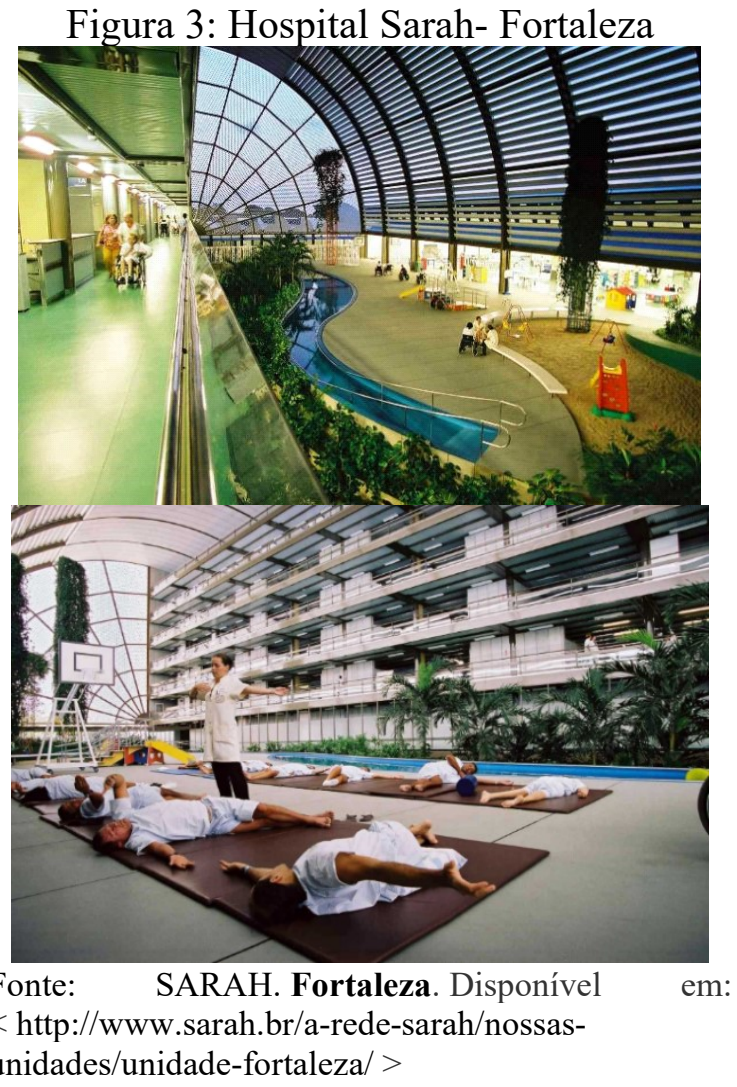

$\mathrm{O}$ arquiteto opta por edifícios mais horizontais com grandes jardins no seu entorno aproximando o usuário do ambiente. Além disso, Lelé mescla sua arquitetura com a arte do artista plástico, Athos Bulcão, através dos seus painéis coloridos que buscam sensibilizar os pacientes e estimulá-los de forma positiva, mediante o contato com as cores das obras de arte, auxiliando o processo de cura do paciente (LUKIANTCHUKI e SOUZA, 2010).

Mesmo que o ambiente hospitalar tenha que controlar infecções, possuir certo fluxo, comportar pessoas e equipamentos, deve também prover saúde, mostrar acolhimento e contribuir com o tratamento do paciente (VIANNA et al.,2008).

Exemplos como esses devem ser repetidos em todos os ambientes de saúde, dado que a criação de ambientes mais humanizados auxilia no tratamento do paciente, tornando sua estadia no hospital mais agradável, facilitando assim o processo de cura. 


\section{PROCESSOS METODOLÓGICOS: MATERIAIS E MÉTODOS}

Este trabalho dividiu-se em três partes, no primeiro momento, foi realizada uma revisão bibliográfica buscando $\mathrm{o}$ fornecimento de base conceitual a respeito da importância da humanização e como ela auxilia no tratamento dos pacientes.

$\mathrm{Na}$ segunda etapa, foram levantados estudos de casos de hospitais brasileiros que utilizam os conceitos estudados, tornando seus ambientes mais confortáveis e humanizados. $\mathrm{Na}$ terceira parte, foram realizadas visitas técnicas a hospitais capixabas. A cidade de Colatina, localizada na região Centro-Oeste do Espírito Santo é a delimitação espacial da pesquisa.

As pesquisas seguiram a metodologia de uma análise exploratória, na qual pretende proporcionar maior proximidade com o problema, tendo como objetivo fundamental o aperfeiçoamento de ideias ou também a descoberta de intuições, conforme explicadas por Gil (2002), seguindo a característica de estudo de caso instrumental. Este método de análise do objeto de estudo reflete as preocupações de pesquisadores em relação ao tema aplicados nos estudos de casos (ALVES-MAZZOTTI, 2006).

Para as análises realizadas através das visitas, utilizou-se da Matriz FOFA (Fortalezas, Oportunidades, Fraquezas e Ameaças) que consiste em um instrumento que auxilia na sistematização e observação dos pontos considerados fortes e frágeis do objeto de estudo (GOMIDE et al., 2015). Após a coleta e análise dos dados obtidos é permitido que sejam identificados os problemas dentro do espaço e possibilita a criação de uma nova diretriz a fim de solucionar os itens desejados dentro do âmbito arquitetônico em concordância com o Plano Nacional de Humanização (PNH) do Ministério da Saúde, através da cartilha Humaniza SUS (BRASIL, 2010). Em campo, usou-se uma ficha técnica com os itens a serem explorados para facilitar a observação e análise posterior (Figura 4).
Figura 4: Ficha técnica usada nas análises

\begin{tabular}{|c|c|c|}
\hline \multicolumn{3}{|c|}{ Hospital analisado: } \\
\hline \multicolumn{3}{|c|}{ Fata da visita: } \\
\hline \multicolumn{2}{|c|}{ ANÁLISE TÉCNICA } \\
\hline Vegetação & CONTÉM & NÄO CONTÉM \\
\hline Arte & & \\
\hline Áreas para descontração & & \\
\hline Música ambiente & & \\
\hline Fonte de luminação natural & & \\
\hline Fonte de ventilação natural & & \\
\hline Cor & & \\
\hline Individualidade & & \\
\hline
\end{tabular}

Observações:

Fonte: Autores (2019)

\section{RESULTADOS E DISCUSSÃO}

Dentro do recorte geográfico determinado para estudo, neste trabalho foram analisados quatro hospitais em Colatina-ES, serão nomeados no trabalho como Hospital particular A, Hospital filantrópico $\mathrm{B}$, ou seja, que oferece atendimentos públicos e privados, Hospital público $\mathrm{C}$ e Hospital filantrópico D. Para essa análise foi utilizada a matriz FOFA que consiste em um instrumento que auxilia na sistematização e observação dos pontos considerados fortes e frágeis do objeto de estudo (GOMIDE et al., 2015). Foi destacado de verde as fortalezas, de laranja as fraquezas, de azul as oportunidades e de cinza as ameaças (Quadro 3). Todos possuem itens de humanização conforme a Cartilha Humaniza SUS (BRASIL, 2010). 
Quadro 3: Utilização da matriz FOFA para análise das observações. Continua.

\begin{tabular}{|c|c|c|c|}
\hline $\mathrm{A}$ & B & $\mathrm{C}$ & $\mathrm{D}$ \\
\hline $\begin{array}{l}\text {-Uso de } \\
\text { iluminação } \\
\text { e ventilação } \\
\text { natural. } \\
\text { - } \\
\text { Intervenções } \\
\text { artísticas. } \\
\text {-Vegetação. }\end{array}$ & $\begin{array}{l}\text { - Inserção } \\
\text { de natureza } \\
\text { dentro da } \\
\text { edificação. } \\
\text { - Quadros. } \\
\text { - Uso dos } \\
\text { condicio- } \\
\text { nantes } \\
\text { naturais. } \\
\text { - Analogia } \\
\text { à hoteis }\end{array}$ & $\begin{array}{l}\text { - } \\
\text { Vegetação } \\
\text { na parte } \\
\text { externa. } \\
\text { - Presença } \\
\text { de cor. } \\
\text { - Espaço } \\
\text { de } \\
\text { distração. }\end{array}$ & $\begin{array}{l}\text { - Uso da } \\
\text { iluminação } \\
\text { natural em } \\
\text { alguns } \\
\text { espaços. } \\
\text { - Presença } \\
\text { de cor e } \\
\text { espaço } \\
\text { infantil. }\end{array}$ \\
\hline $\begin{array}{l}\text { - Paredes } \\
\text { Brancas. } \\
\text { - Apesar de } \\
\text { conter } \\
\text { vegetação, } \\
\text { encontrou- } \\
\text { se poucas } \\
\text { unidades. } \\
\text { - Falta de } \\
\text { elementos } \\
\text { artísticos. }\end{array}$ & $\begin{array}{l}\text { - Não foi } \\
\text { encontrado } \\
\text {. }\end{array}$ & $\begin{array}{l}\text { - } \\
\text { Edificação } \\
\text { patologias. } \\
\text { - Ausência } \\
\text { de } \\
\text { elementos } \\
\text { artísticos. } \\
\text { - Ausência } \\
\text { de } \\
\text { vegetação } \\
\text { na parte } \\
\text { interna. } \\
\text { - Pouco } \\
\text { uso da } \\
\text { Iluminação } \\
\text { e } \\
\text { ventilação } \\
\text { natural. } \\
\text { - Espaço } \\
\text { de } \\
\text { distração } \\
\text { em local } \\
\text { muito } \\
\text { quente. }\end{array}$ & $\begin{array}{l}\text { - Falta de } \\
\text { janelas em } \\
\text { certos } \\
\text { locais, } \\
\text { dificultan- } \\
\text { do a noção } \\
\text { de } \\
\text { temporali- } \\
\text { dade. } \\
\text { - Ausência } \\
\text { de } \\
\text { vegetação. } \\
\text { - Ausência } \\
\text { de } \\
\text { elementos } \\
\text { artísticos. }\end{array}$ \\
\hline $\begin{array}{l}\text { - Potencial } \\
\text { para maior } \\
\text { uso de } \\
\text { elementos } \\
\text { artísticos e } \\
\text { vegetação. }\end{array}$ & $\begin{array}{l}\text {-Grandes } \\
\text { paredes } \\
\text { brancas } \\
\text { com } \\
\text { potencial } \\
\text { de uso de } \\
\text { arte. }\end{array}$ & $\begin{array}{l}\text { - Potencial } \\
\text { para a } \\
\text { inserção de } \\
\text { elementos } \\
\text { artísticos. } \\
\text { - Criação } \\
\text { de locais } \\
\text { mais } \\
\text { agradáveis } \\
\text { aos } \\
\text { usuários, } \\
\text { com } \\
\text { inserção de } \\
\text { vegetação, } \\
\text { condiciona } \\
\text { ntes } \\
\text { naturais e } \\
\text { arte. }\end{array}$ & $\begin{array}{l}\text { - Potencial } \\
\text { para maior } \\
\text { uso de } \\
\text { elementos } \\
\text { artísticos e } \\
\text { vegetação. } \\
\text { - Criação } \\
\text { de } \\
\text { ambientes } \\
\text { de } \\
\text { descontra- } \\
\text { ção. }\end{array}$ \\
\hline Atualmente, & $\begin{array}{l}\text { - Não foi } \\
\text { encontrado }\end{array}$ & Atualmen- & - \\
\hline
\end{tabular}

\begin{tabular}{|c|c|c|}
\hline $\begin{array}{l}\text { pouco } \\
\text { potencial } \\
\text { para } \\
\text { trabalhar a } \\
\text { cura do } \\
\text { paciente. }\end{array}$ & $\begin{array}{l}\text { te, pouco } \\
\text { potencial } \\
\text { para } \\
\text { trabalhar a } \\
\text { cura do } \\
\text { paciente. }\end{array}$ & $\begin{array}{l}\text { te, pouco } \\
\text { potencial } \\
\text { para } \\
\text { trabalhar a } \\
\text { cura do } \\
\text { paciente. }\end{array}$ \\
\hline
\end{tabular}

Fonte: Elaborada pelos autores (2019)

Através das análises pelo método da matriz FOFA, observou-se que há várias fragilidades ainda dentro dos espaços de saúde do município, não caracterizando a maioria dos espaços como sendo humanizados. Nota-se ainda que há uma nítida diferença na humanização encontrada na instituição privada com as da rede pública, entretanto, apesar de alguns hospitais constarem pontos de humanização, é importante que se entenda que há muito que ser feito visando tornar o ambiente mais humanizado e consequentemente auxiliar de maneira mais eficaz a cura do paciente. Todavia, vê-se que o conceito tem se tornado mais presente, mesmo que de forma discreta em alguns locais.

Os Hospitais A, C e D não são considerados humanizados, visto que faltam muitos pontos incluídos na cartilha, o que torna o ambiente mais distante do paciente, apesar de utilizarem alguns itens, como o uso dos condicionantes naturais. Nesses hospitais há uma grande lacuna no que diz respeito a elementos artísticos, cores e vegetação dentro da edificação, aparecendo de forma pontual em alguns espaços. Além disso, no Hospital C, observa-se várias patologias nas paredes, remetendo a sensação de descaso com o espaço físico e consequentemente aos usuários que utilizam seus serviços. Ainda, no Hospital D, há a falta de janelas em alguns ambientes, dificultando ao paciente ter noção da passagem do tempo. Como analisado através da matriz FOFA, esses espaços de saúde possuem potencial para a inserção dos elementos característicos da humanização, como grandes paredes brancas que poderiam ser acrescidas de cores e quadros, além de retratos de paisagens naturais em locais sem esquadrias, Nanda et al. (2011) destaca que a observação de obras de arte pode ter grande impacto na saúde e que 
imagens com teor positivo e calmante da natureza tem caráter terapêutico, tornando assim, esses ambientes mais agradáveis.

As cores também possuem função terapêutica, como o verde que remete a harmonia, proporcionando calmaria e o azul que expressa tranquilidade, auxiliando na redução da pressão arterial (LACY, 1996). Sendo assim, o uso de cores adequadas para cada espaço ajudaria na criação de uma nova ambiência.

Também, faz-se necessário a criação de locais descontraídos para todos que usufruirão do espaço, sejam eles pacientes, acompanhantes ou até mesmo profissionais, com o intuito de criar interação entre os mesmos e transferir o foco da doença para o paciente. Para a criação desses espaços, Horevicz e De Cunto (2018) recomendam o uso de mobiliários móveis, a fim de estimular a interação social e reuniões de grupos. Ainda, o autor menciona que a presença de átrios e jardins internos ou externos com possibilidade de visualização do interior, podem proporcionar distrações positivas.

O Hospital B, possui todos os pontos analisados de acordo com a cartilha, como o uso se vegetação, cores, quadros com temas diversos, aproveitamento dos condicionantes naturais, bem como locais que permitem a descontração trazendo maior bem-estar aos usuários, refletindo a diferença que ainda ocorre no conceito de humanização entre os hospitais da rede privada com a pública no município de Colatina (Figura 5).
Figura 5: Vegetação nos jardins internos e nas áreas de espera no Hospital B.

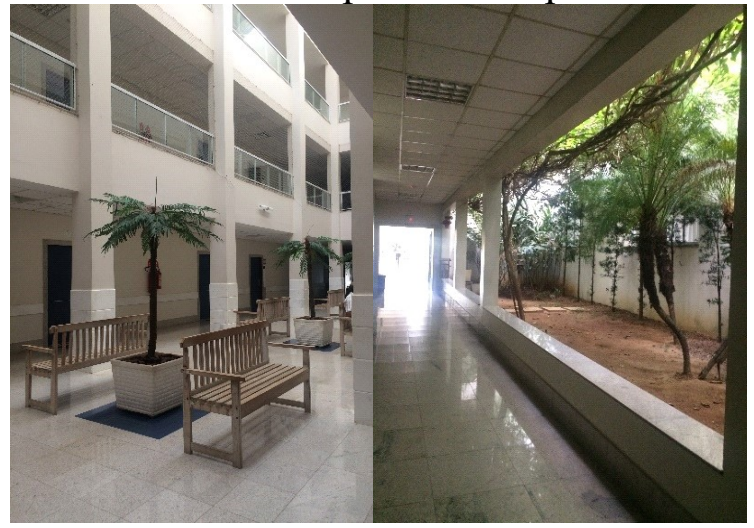

Fonte: Autores (2019)

O ambiente físico deve ser considerado como agente influenciador para a saúde dos usuários, sendo assim, é necessário que todas as instituições, sendo elas particulares ou públicas, valorizem a importância da humanização para aplicar estes conceitos em seus espaços e proporcionar maior bem-estar aos seus pacientes, auxiliando no seu processo de cura e tornando seu tratamento mais agradável.

\section{CONCLUSÕES}

Entende-se que a humanização é uma ferramenta auxiliadora para a resolução de problemas decorridos da impessoalidade das redes hospitalares. Diversos estudos na área da saúde têm abordado o tema dentro da humanização na prática assistencial, entretanto, há poucas pesquisas no que concerne ao ambiente humanizado, a respeito de como $\mathrm{o}$ ambiente físico hospitalar influencia no tratamento do paciente.

Como meio de reverter essa situação, o Ministério da saúde, criou uma cartilha, "Humaniza SUS", visando mostrar a importância e os meios de como humanizar os hospitais, mas ainda se veem vários exemplos que não colocam em prática tais conceitos.

Através da matriz FOFA pôde-se observar que o atual cenário dos hospitais do município de Colatina- ES ainda não pode ser considerado humanizado, visto que 
existem muitas fragilidades apontadas. É importante ressaltar que apesar de algumas características serem pontuadas como encontradas nos hospitais analisados, como nos hospitais A, C e D, ainda há uma grande falta de quesitos para tornar o ambiente mais humanizado em relação aos itens estudados. Nota-se que apesar da cartilha ser feita pelo governo, os hospitais da rede pública analisados ainda não atendem a maioria dos itens previstos para

\section{REFERÊNCIAS}

ALVES-MAZZOTTI, Alda Judith. Usos e abusos de estudos de

caso. Cad. Pesqui. São Paulo, v. 36, n. 129, p. 637-651, dez. 2006. Disponível em

$<\underline{\text { http://www.scielo.br/scielo.php?script }=\text { sc }}$ $\mathrm{i}$ arttext\&pid $=\mathrm{S} 0100$ $15742006000300007 \& \operatorname{lng}=$ en\&nrm=iso $>$.

Acesso em 23 de abril de 2019.

http://dx.doi.org/10.1590/S0100-

15742006000300007.

BATES, Victoria. 'Humanizing' healthcare environments: architecture, art and design in modern hospitals, Design for

Health, 2:1, 5-19, 2018.

DOI: $10.1080 / 24735132.2018 .1436304$.

BESTETTI, Maria Luisa Trindade.

Ambience: built environment and behavior. Rev. bras. geriatr. gerontol., Rio de Janeiro, v. 17, n. 3, p. 601-610, Sept. 2014 . Available from $<$ http://www.scielo.br/scielo.php?script $=\mathrm{sC}$ $\mathrm{i}$ arttext\&pid=S180998232014000300601\&lng=en\&nrm=iso $>$. Acesso em 23 de abril. 2019. http://dx.doi.org/10.1590/18099823.2014.13083.

BRASIL. Ministério da Saúde. Secretaria de Atenção à Saúde. Núcleo Técnico da Política Nacional de Humanização. Ambiência / Ministério da Saúde, Secretaria de Atenção à Saúde, Núcleo proporcionar o bem-estar do paciente e assim auxiliar no processo de cura.

\section{AGRADECIMENTOS}

Agradecemos aos hospitais colatinenses por permitirem as visitas e análises dentro de suas estruturas. Além disso, agradecemos ao IFES- Campus Colatina pela oportunidade de realizar esta pesquisa através do edital 05/2018.

Técnico da Política Nacional de Humanização. - 2. ed. - Brasília : Editora do Ministério da Saúde, 2010. 32 p. (Série B. Textos Básicos de Saúde).

BROMLEY, Elizabeth. Construindo a centralidade do paciente: o design do hospital como um ato interpretativo. Ciências Sociais e Medicina, v. 75, n. 6, p. 1057-1066, 2012.

CAVALCANTE, S.; ELALI, G.A. (org.). Temas Básicos em Psicologia Ambiental. Petrópolis: Vozes, 2011, 318p. DESLANDES, Suely F. Análise do discurso oficial sobre a humanização da assistência hospitalar. Ciênc. saúde coletiva [online]. 2004, vol.9, n.1, pp.7-14. ISSN 1413-8123.

http://dx.doi.org/10.1590/S141381232004000100002 .

FOUCAULT, Michel. Microfísica do poder. Rio de janeiro, Editora Graal, 1989, p. 99

GIL, ANTÔNIO CARLOS. Como elaborar projetos de pesquisa. 4 . Ed. São Paulo: Atlas, 2002, 175p.

GOMIDE, Marcia et al. Fortalezas, Oportunidades, Fraquezas e Ameaças (Matriz FOFA) de uma Comunidade Ribeirinha Sul-Amazônica na perspectiva da Análise de Redes Sociais: aportes para a Atenção Básica à Saúde. Cadernos Saúde Coletiva, [s.1.], v. 23, n. 3, p.222-230, set. 2015. FapUNIFESP (SciELO). 
http://dx.doi.org/10.1590/1414$462 \times 201500030089$.

HALL, Edward. A dimensão oculta. Trad. Sônia Coutinho. Rio de Janeiro: Francisco Alves, 1977.

HOREVICZ, Elisabete Cardoso Simão; DE CUNTO, Ivanóe. A humanização em interiores de ambientes hospitalares. Revista Terra \& Cultura: Cadernos de Ensino e Pesquisa, v. 23, n. 45, p. 17-23, 2018.

LACY, Marie Louise. O poder das cores no equilíbrio dos ambientes. São Paulo: Pensamento, 1996. 147p.

LA FUENTE, Javier Antonio Alvarino de. O edifício doente: Relação entre construção, saúde e bem-estar. 2013. 106 f. Tese (Doutorado) - Curso de Arquitetura e Urbanismo, Universidade de Minho, Minho-Portugal, 2013.

LIMA, João Filgueiras. O que é ser arquiteto: memórias profissionais de Lelé (João Filgueiras Lima). Depoimento a Cynara Menezes. Rio de Janeiro, Record, 2004, p. 50.

LOPES, Maria Alice; MEDEIROS, Luciana de. Humanização hospitalar: origem, uso e banalização do termo.

Revista Online Propec Iab Mg, Minas Gerais, v. 1, p. 2, 2004.

\section{LUKIANTCHUKI, Marieli Azoia;}

CARAM, Rosana Maria. Análise do conforto térmico na obra de João Filgueiras Lima, Lelé: hospitais Sarah de Salvador e do Rio de Janeiro. Paranoá: cadernos de arquitetura e urbanismo, $\mathrm{n}$. 12, 2014.

DOI: https://doi.org/10.18830/issn.16790944.n12.2014.12209.

LUKIANTCHUKI, Marieli A.; SOUZA, Gisela B. de. Humanização da arquitetura hospitalar: entre ensaios de definições e materializações híbridas. VITRUVIUSArquitextos-118.01 ano, v. 10, 2010. MIQUELIN, Lauro. Um lindo hotel parece um hospital, Projeto design, nov., 1997, p. 104-107.

NANDA, U., EISEN, S. ZADEH, R. S. and OWEN, D. (2011), Effect of visual art on patient anxiety and agitation in a mental health facility and implications for the business case. Journal of Psychiatric and Mental Health Nursing, 18: 386-393. doi:10.1111/j.1365-2850.2010.01682.x.

Nardin A. L'humanisation de L'hôpital. Mode D'emploi. Paris: Broché. 2009.

NEVES, Juliana Duarte. Arquitetura Sensorial. Rio de Janeiro: Mauad, 2017. $188 \mathrm{p}$.

MARTORELLI, CAMILA MENDES. Acústica na ambiência dos CAPS AD: a influência de componentes sonoros no processo terapêutico. In: Encontro Nacional e Latino-Americano de Conforto no Ambiente Construído (ENCAC/ELACAC), 2015, Campinas. Encontro Nacional e Latino-Americano de Conforto no Ambiente Construído (ENCAC/ELACAC), 2015.

PALLASMAA, Juhani. Os olhos da Pele: A arquitetura e os sentidos. Porto Alegre: Bookman, 2011. 104 p.

PINHEIRO, José Queiroz. Psicologia Ambiental: entendendo as relações do homem com o seu ambiente. Campinas, SP: Editora Alínea, 2006.

RAMOS, Katiúcia Megda; LUKIANTCHUKI, Marieli Azoia. Edifícios hospitalares: A contribuição da Arquitetura na cura.. In: ENCONTRO INTERNACIONAL DE PRODUÇÃO CIENTÍFICA UNICESUMAR, 9., 2015, Maringá. Anais Eletrônico. Maringá-PR: Unicesumar, 2015. p. 1 - 10. 
ULRICH, Roger. S. Effects of health facility interior design on wellness: theory and scientific research. Journal of Health Care Design, v.3, p.97-109, 1991.
VIANNA, Luciana de Medeiros;

SANTOS, M.; BURSZTYN, I. .

Ambientes de saúde: o estado da arte da arquitetura hospitalar frente aos desafios contemporâneos. Cadernos Saúde

Coletiva (UFRJ), v. 16, p. 7-20, 2008. 